THE most notable feature of the current outbreak of rabies in Europe is the involvement of wildlife. When the disease was eliminated from Britain and certain other European countries at the turn of the century, rabies had been maintained in the domestic dog. Now it is the fox population which acts as a reservoir of infection.

Whatever the reason, this new factor makes the present outbreak difficult to stem. As Britain's foxes are now more numerous than ever before, everything possible must be done to keep the disease away from them.

Rabies could reach Britain in two ways: a domestic animal incubating the disease might be landed illegally or an infected wild creature could make its way here under its own steam. The former is much more likely but although we can discount tales of rabid foxes attempting the channel swim, the second should not be ignored.

Bats can harbour rabies and certain species are known to arrive in Britain from the continent (the common longeared bat, for example, migrates from Scandinavia to Yorkshire). Surprisingly, although rats are susceptible to rabies and carry other diseases from country to country on board ship, for some reason they have not yet brought rabies here. But as the distance between endemic areas of wildlife rabies and Britain diminishes, the likelihood of infection reaching us in these ways, however slight, must increase. And apart from greater vigilance against any animal stowaways, there is little that can be done to prevent it.

Illegal importation is another matter. According to a recent survey by the Ministry of Agriculture, Fisheries and Food (MAFF), 110 dogs, cats and other animals were landed illegally last year at the Kent ports alone. How many escaped detection is, of course, anyone's guess. Each of these animals might have been infected with rabies (some had been adopted only hours before the crossing) and transmitted the disease to pets and wildlife here. Although the report calls for greater deterrents against would-be smugglers, the greatest hope of keeping rabies out of Britain seems to lie in alerting the public to the dangers of the disease and in explaining why quarantine procedures are needed to prevent its entry.

And the public do need education; Britain has been free from rabies for several generations now and many people seem to think of it as a "disease of mad dogs". They have forgotten that rabies is almost always fatal in man once the symptoms appear-only two cures have ever been recordedand so hideous are the agonies of the victim that euthanasia was once the common 'remedy'.

Nor are they aware of the regulations governing the importation of any animals they may acquire while on holiday. It is illegal to land an animal in Britain without an import licence and that is only given to owners who have made arrangements for six months' quarantine. Landing is held to have taken place before customs examination

\section{Mad dogs and Englishmen}

The present epidemic of rabies in Europe is still spreading westwards and has now reached northern France; it could enter Britain. John Wilson has been looking at the risks to this country.

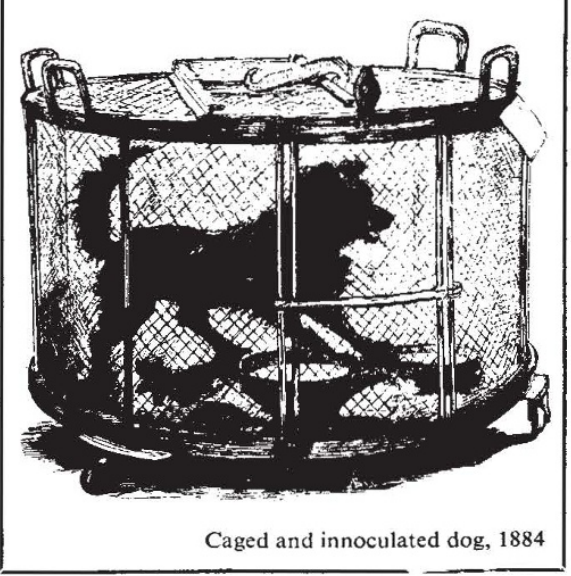

so even those people who declare their pet have committed an offence.

Official action in Kent last year prevented the entry of 33 animals but 10 evaded the port controls completely and were only detected inland (or on their way out of the country again). In all the other cases, it was the owners themselves who took action that prevented the animals from entering - and thus showed their ignorance of the law.

Customs officers reckoned that about 20 animals had been deliberately concealed. Perhaps the owners did so to avoid paying quarantine fee (about $£ 120$ for a $\mathrm{dog}$ ) or perhaps from a misplaced sympathy of animals in quarantine. In either case, the fines handed out to the offenders (average £40) were hardly a deterrent. But under the Rabies Act (1974) fines have now been increased- $£ 200$ or more in some cases -and the local authority can have the animal summarily destroyed.

But if the worst comes to the worst how would Britain react to an outbreak? If pets or farm animals evaded quarantine there is some chance that the animal would be discovered before the disease had been transmitted to wildlife and to foxes in particular. That would be bad enough: family pets destroyed, valuable animals lost and people subjected to pain and anxiety. But if the disease did spread to the fox population things would be grave indeed. Continental workers have shown that rabies will still survive amongst foxes until their numbers are reduced to about 0.5 individuals per square kilometre. At this point the chances of a rabid fox infecting one of its fellows before it dies begin to peter out. Following the example of other European countries, the government would adopt a 'killer' policy, however unpopular it might be with some environmentalists.

With the exception of Denmark and possibly Belgium, this 'killer' policy has not met with much success. In France the disease is advancing along a front nearly $800 \mathrm{~km}$ long at the rate of roughly $30 \mathrm{~km}$ each year. To halt it would require a high degree of control over the fox numbers in a belt about $60 \mathrm{~km}$ deep-a prodigious effort. Britain is isolated, however, and the disease could be eliminated before it had taken a firm hold.

Plans are already prepared. Scientists from MAFF calculate that an area of about 12 miles radius around an outbreak of rabies would need to be virtually cleared of foxes. But before the hunting fraternity reach for their stirrups they should know that their activities would not be welcome for they could drive infected animals out of the area. An intensive poisoning campaign seems best.

Not everyone believes that the introduction of rabies to this country is inevitable but it is perhaps just as well that a new vaccine will soon be ready to treat any British victims of the disease. Developed at the Wistar Institute and produced at the Mérieux Institute in France the new killed virus vaccine is prepared from cultures of WI38 human tissue culture. Unlike vaccines now in use, such as the Duck Embryo Vaccine, it contains virus antigens and very little else-rather like the Salk polio vaccine. This should ensure that the incidence of side effects to vaccination will be greatly reduced.

Although trials of the WI38 vaccine are not yet complete the initial results are very promising. Even one injection quickly produces a very high titre of antibodies. The vaccine is expensive compared with conventional rabies vaccines but work is being done at the Clinical Research Centre, Harrow, to improve the dose regimen.

If the new vaccine passes its clinical trials only one painless vaccination in the arm would be necessary rather than the traditional 14 or so painful abdominal vaccinations now required. But no matter what improvements in treatment are on the way they are no excuse to take liberties with such a distressing and expensive disease. 